\title{
Violência doméstica e familiar contra a mulher no contexto educacional
}

\author{
Domestic and family violence against women in the educational \\ context
}

\author{
Priscila Bernardo de Oliveira \\ Universidade Federal de Jataí
}

\begin{abstract}
Resumo: Este artigo trata da importância de abordar a temática da violência doméstica e familiar contra a mulher (VDFM) e de problematizar esse assunto no ambiente educacional com enfoque na formação continuada de educadores. Por meio de uma revisão bibliográfica e documental e a partir de uma metodologia qualitativa com viés materialista histórico, foi possível compreender a constituição do desenvolvimento humano e as relações que o permeiam. Por ser uma questão cultural e presente na sociedade brasileira, razão pela qual é fundamental que o tema seja discutido nas escolas da rede estadual de ensino das cidades de Jataí e Rio Verde, no estado de Goiás, por seu caráter formativo e socializador, a violência contra a mulher deve ser interpelada com base em uma educação holística e democrática, fator fundamental para sua prevenção e seu enfrentamento.
\end{abstract}

Palavras-chave: Educação; Mulheres; Violência Doméstica.

Abstract: This article addresses the importance of addressing the issue of domestic and family violence against women (VDFM) and problematizing this practice in the educational environment with a focus on the continuing education of educators. Through a bibliographical and documentary review and from a qualitative methodology with a historical materialist bias, it was possible to understand the constitution of human development and the relationships that permeate it. Because it is a cultural issue and present in Brazilian society, which is why it is essential that the topic be discussed in state schools in the cities of Jataí and Rio Verde, in the state of Goiás, due to its formative and socializing character, violence against women must be challenged on the basis of holistic and democratic education, a fundamental factor for their prevention and confrontation.

Keywords: Education; Women; Domestic Violence. 


\section{INTRODUÇÃO}

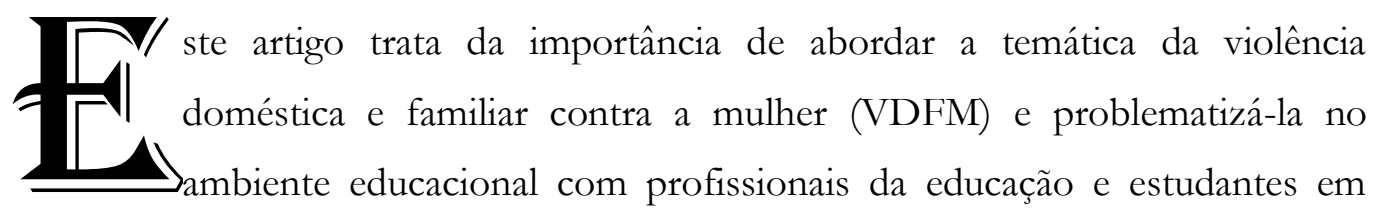
fase de desenvolvimento das escolas públicas estaduais das cidades de Jataí e Rio Verde, no estado de Goiás. Essa abordagem é necessária quando se observa a relevância do papel escolar em propiciar o domínio de recursos capazes de levar à discussão assuntos de tal magnitude, de forma crítica, para promover a participação social e política.

Refletir a respeito da violência doméstica e familiar contra a mulher desperta conhecimentos que se inserem no escopo da construção dos modos de prevenir a violência nos lares, proteger a si mesmo e a seus familiares. Sendo assim, para compreender o contexto em que ocorre esse tipo de violência, é necessário realizar uma breve retomada histórica do percurso da educação no Brasil e dos processos formativos que se deram em moldes patriarcais e de prevalência do masculino sobre o feminino.

Desde o período colonial, a preocupação com a educação no país por parte da nobreza e da Igreja Católica - até então detentoras do sistema de ensino - era catequizar os nativos para obter mão de obra e fiéis. Contudo, após a expulsão dos jesuítas, Marquês de Pombal, então primeiro-ministro do reinado de D. José I (1714-1777), pretendia instalar um ensino laico, que convinha com os interesses comerciais de Portugal. Esses fatos demonstram que a educação esteve, desde seus primórdios, à mercê de interesses econômicos.

Posteriormente, a educação passa a ser uma questão discutida nacionalmente após a queda das oligarquias do período imperial. Segundo Patto (1988), a passagem gradativa da sociedade oligárquica para a promessa de uma sociedade urbana/industrial e capitalista aumentou a demanda de mão de obra escolarizada e qualificada, bem como o número de escolas que deveriam ter a frequência gratuita e obrigatória, conforme a Constituição do Império.

Paralelo a esse momento de Revolução Industrial, surge a "escola ativa" (MANACORDA, 1999, p. 311), um grande e generalizado movimento de democratização da educação que se constituiu como um passo importante para mudança educacional. Apesar disso, atualmente, a educação continua a ser submetida à vontade da classe dominante, com a implantação de medidas ideológicas e políticas governamentais que deveriam ser políticas de Estado. 
A frequência de estudantes na escola, antes privilégio apenas de alguns, agora é, pelo menos teoricamente, direito de todos. E a instituição de ensino, considerada um capital, passou a gerar lucro e desenvolvimento com a força de trabalho que produz (PATTO, 1988). Como educação é poder, a reação das elites para manter os privilégios conquistados não tardou, e as escolas de caráter privado tiveram lugar de destaque na oferta de qualidade superior. Assim, os dois modelos de ensino, ou seja, o público e o privado, passaram a conviver de modo não tão harmônico.

Para dar base a este estudo é válido pontuar que ele segue na direção da construção do desenvolvimento humano e das relações indispensáveis que o permeiam. Para corroborar os conceitos tratados, a abordagem histórico-cultural é discutida a partir dos fundamentos de Lev Vygotsky, cujos estudos são baseados no materialismo histórico.

Manacorda (1991), ao citar Karl Marx, afirma que o trabalho é uma importante atividade para o homem, pois faz com que ele se relacione com a natureza e com outros homens, modificando-os ao modificar-se, explica que a educação deve ser pensada como dimensão da vida social em um processo abrangente e permanente. Ao visar o trabalho como fundamento ontológico na constituição do ser social, o homem se diferencia dos demais seres naturais, haja vista que a educação exerce fator decisivo em sua formação.

Corroborando as ideias de Marx, Mészáros (2002) acrescenta que a educação de forma isolada e/ou ideologizada não oferta emancipação, mas produz conformidade e consenso se não estiver vinculada a outras esferas que integre, produza dissenso e capacidade crítica. Segundo o autor, "[...] é por isso que, também no âmbito educacional, as soluções não podem ser formais; elas devem ser essenciais. Em outras palavras, elas devem abarcar a totalidade das práticas educacionais da sociedade estabelecida" (MÉSZÁROS, 2002, p. 45).

A formação educacional formal e não formal de crianças e adolescentes é uma luta constante, já que sua oferta possui limitações impostas pelo próprio Estado. Sendo assim, a proposta de análise da violência doméstica e familiar contra a mulher surge do pressuposto de que existem situações complexas no contexto sociojurídico e dos projetos de lei que abordam o tema no meio educacional, visando auxiliar e orientar profissionais da área a desenvolverem e tratarem do assunto, além de contribuírem com a formação adequada e ampliada acerca dessa problemática.

Ao possibilitar, de fato, a elaboração da educação essencial para o desenvolvimento da vida de crianças e adolescentes em fase de formação humana marcada por intensas mudanças decorrentes de transformações biológicas, psicológicas, 
sociais e emocionais -, busca-se, como aponta o Parecer CNE/CEB n 11/2010, ampliar os vínculos sociais e laços afetivos, as possibilidades intelectuais e a capacidade de raciocínios mais abstratos. Desse modo, os estudantes tornam-se capazes de ver e avaliar os fatos pelo ponto de vista do outro, exercendo a capacidade de descentração, aspecto "[...] importante na construção da autonomia e na aquisição de valores morais e éticos" (BRASIL, 2010).

\section{A VIOLÊNCIA DOMÉSTICA E FAMILIAR CONTRA A MULHER NA SOCIEDADE BRASILEIRA}

$\mathrm{Na}$ sociedade contemporânea brasileira, a violência doméstica e familiar está presente em todos os níveis econômicos e sociais. Embora seja um fenômeno recorrente, com consequências negativas tanto para o agressor quanto para a vítima, esse tipo de violência frequentemente não se apresenta e é, ao mesmo tempo, sistematicamente escondida e não discutida de maneira ampla e adequada. Além disso, quanto mais alta a classe social, mais o assunto é considerado íntimo e privativo do seio familiar.

Para Fernandes (2005), a representação dos papéis de superioridade gera a aceitação da violência doméstica como algo quase natural ou que em geral se naturaliza e tem raízes na forma de organização social. Para compreensão e definição de violência, a Organização Mundial da Saúde (OMS) conceitua

“[...] o uso intencional de força física ou poder, ameaçados ou reais, contra si mesmo, contra outra pessoa ou contra um grupo ou comunidade, que resultem ou tenham grande probabilidade de resultar em ferimento, morte, dano psicológico, mal desenvolvimento ou privação" (DAHLBERG; KRUG, 2007, p. 1165).

A violência contra a mulher também pode ser entendida, de acordo com a Declaração das Nações Unidas de 1949, aprovada pela Conferência de Viena em 1993, como "[...] todo e qualquer ato embasado em uma situação de gênero, na vida pública ou privada, que tenha como resultado dano de natureza física, sexual ou psicológica, incluindo ameaças, coerção ou a privação arbitrária da liberdade" (ADEODATO et al., 2005). As características do ato violento são diversas, podendo ser desde marcas visíveis no corpo, que resultam na violência física, até formas mais sutis, porém não menos importantes, como a violência psicológica, que traz danos significativos à estrutura emocional da mulher.

A Lei $\mathrm{n}^{\circ}$ 11.340, de 7 de agosto de 2006, também conhecida como Lei Maria da Penha, considera de modo expresso que a violência doméstica e familiar contra a mulher constitui uma das formas de agressão e violação dos direitos humanos. Para tanto, foi 
estabelecido um rol exemplificativo, disposto no art. $7^{\circ}$, sobre violência física, psicológica, sexual, patrimonial e moral:

Art. $7^{\circ}$. São formas de violência doméstica e familiar contra a mulher, entre outras:

I - a violência física, entendida como qualquer conduta que ofenda sua integridade ou saúde corporal;

II - a violência psicológica, entendida como qualquer conduta que lhe cause dano emocional e diminuição da autoestima ou que lhe prejudique e perturbe o pleno desenvolvimento ou que vise degradar ou controlar suas ações, comportamentos, crenças e decisões, mediante ameaça, constrangimento, humilhação, manipulação, isolamento, vigilância constante, perseguição contumaz, insulto, chantagem, violação de sua intimidade, ridicularização, exploração e limitação do direito de ir e vir ou qualquer outro meio que lhe cause prejuízo à saúde psicológica e à autodeterminação;

III - a violência sexual, entendida como qualquer conduta que a constranja a presenciar, a manter ou a participar de relação sexual não desejada, mediante intimidação, ameaça, coação ou uso da força que a induza a comercializar ou a utilizar, de qualquer modo, a sua sexualidade, que a impeça de usar qualquer método contraceptivo ou que a force ao matrimônio, à gravidez, ao aborto ou à prostituição, mediante coação, chantagem, suborno ou manipulação; ou que limite ou anule o exercício de seus direitos sexuais e reprodutivos;

IV - a violência patrimonial, entendida como qualquer conduta que configure retenção, subtração, destruição parcial ou total de seus objetos, instrumentos de trabalho, documentos pessoais, bens, valores e direitos ou recursos econômicos, incluindo os destinados a satisfazer suas necessidades;

$\mathrm{V}$ - a violência moral, entendida como qualquer conduta que configure calúnia, difamação ou injúria. (BRASIL, 2006).

A VDFM é uma questão cultural e gravemente arraigada na sociedade brasileira, razão pela qual educadores que atuam na rede de educação estejam preparados para problematizar, dialogar e orientar os estudantes. A Lei Maria da Penha é considerada recente conforme os aspectos jurídicos, por isso a importância de trabalhar e disseminar seu conteúdo. Além do aspecto jurídico e processual penal e punitivo, essa determinação traz em seu bojo um conjunto de normas que visa proteger a estrutura familiar ao disponibilizar instrumentos e mecanismos para o enfrentamento dos casos, com abordagens de prevenção, proteção das vítimas e responsabilização dos autores. De acordo com a referida normativa, cabe ao Estado brasileiro, por meio de suas instituições e agentes, a elaboração e implementação de políticas públicas eficazes para garantir a segurança da mulher vítima de alguma forma de violência.

Porém, mesmo com o advento da Lei Maria da Penha e seu aspecto punitivo, com a aplicação de penas mais rígidas e medidas protetivas de urgência, não houve uma 
sensível diminuição nos índices de violência doméstica e familiar contra a mulher registrados no Brasil. Dados do Observatório da Mulher Contra a Violência, especialmente no estado de Goiás indicam que o combate e a repressão não são suficientes. Dessa forma, entende-se que a escola é parte fundamental no processo educacional para formação de uma cultura preventiva, responsável por criar nas crianças a compreensão do outro como portador dos mesmos direitos, independente de gênero ou de qualquer outro aspecto e característica.

Pesquisas indicam que, na maioria das vezes, a escola é o primeiro local onde se constatam os reflexos desagregadores do núcleo familiar em razão das agressões perpetradas pelo homem. Por isso, a discussão a respeito do assunto na instituição de ensino é uma das formas indiretas de mudança futura e a possibilidade de que o atendimento e os demais procedimentos que buscam a proteção das vítimas se tornem mais céleres e efetivos para as partes envolvidas. Isso porque parte-se do pressuposto de que a educação é fundamental para prevenção da violência.

Nesse sentido, a escola tem papel imprescindível na desconstrução da aceitação da violência contra a mulher pelas novas gerações. Desse modo, ao levar o conteúdo da Lei $n^{\circ} 11.340 / 2006$ para as escolas, intenta-se trabalhar a formação de uma nova consciência de crianças e adolescentes para que, ao quebrar antigos paradigmas comportamentais, eles se tornem verdadeiros agentes transformadores da realidade e promovam a transformação e emancipação dos sujeitos da educação, posto que estudar e debater questões relativas à violência doméstica favorecem a compreensão de como são construídas as relações entre meninos e meninas que se tornarão homens e mulheres.

As ações de enfrentamento das formas de violência na perspectiva educacional preventiva precisam se fortalecer com enfoque na desconstrução da cultura em desfavor do gênero feminino - historicamente assentida no meio social. De fato, esse fenômeno na cultura brasileira e goiana, em particular, existe e necessita ser debatido para construir a cultura do respeito, da consideração e da empatia. Cabe, portanto, às instituições de ensino e ao poder público promover um olhar crítico entre estudantes, professores e a comunidade escolar, a partir das noções de igualdade de gênero e práticas de prevenção contra violência doméstica e familiar. Vale enfatizar a importância do aprendizado sobre o tema para desconstrução histórica do patriarcado enraizado na sociedade brasileira.

\section{METODOLOGIA}


O método utilizado para desvelar o tema da VDFM é baseado no materialismo histórico, o qual consiste em compreender o maior número de nexos que envolvem a temática, especialmente no que se refere às dimensões histórica, econômica, social, cultural e educacional, para verificar como se dá a gênese da violência de gênero e as imbricações que se entrelaçam nas representações sociais do papel da mulher, sua importância e lugar na sociedade opressora e patriarcal brasileira, que naturaliza a violência física, patrimonial, sexual, moral e emocional em níveis que se agravam cada vez mais nos dias de hoje. Para tanto, o estudo apresenta uma abordagem qualitativa e enfoque sócio-histórico coerentes com a teoria dialética de compreensão dos fenômenos humanos. Também se utiliza de uma pesquisa bibliográfica e documental de dados com intuito de obter mais informações acerca do tema (LAKATOS; MARCONI, 2013, p. 44).

\section{RESULTADOS E DISCUSSÕES}

Há diversas legislações que abordam o direito à educação, dentre elas a Constituição Federal de 1988, a Lei de Diretrizes e Bases da Educação (LDB) de 1996, o Estatuto da Criança e do Adolescente (ECA) de 1990 e o Plano Nacional de Educação (PNE), além da própria Lei no 11.340/2006, que garantem à criança e ao adolescente direitos que precisam ser seguidos por profissionais dentro e fora do contexto escolar. Nos campos da Psicologia, da Sociologia e da Educação Escolar, o presente artigo se utiliza da visão sócio-histórica de Vygotsky, recorrendo a sua explicação acerca da Psicologia, um desafio que se coloca a partir do mundo objetivo para construir o mundo subjetivo do indivíduo, sem reduzir o homem ao pensamento e à ação, com foco nas relações sociais, que, colocadas à luz de disciplinas correlatas ou próximas, permitem compreender aspectos que evidenciam a originalidade da pesquisa interdisciplinar.

Os estudos de Vygotsky se pautam na melhor forma de compreender como se faz a transformação da natureza social para a psicológica de um indivíduo (ANTUNES; MEIRA, 2003, p. 36). Para ele, o que nos diferencia dos animais e nos faz homens é, dentre várias outras questões, a capacidade de mediar nossas relações, já que a constituição humana se forma pela dupla estimulação, que consiste em um plano interpessoal (pautado no indivíduo antes do social) e outro intrapessoal (quando o aprendizado é modificado pelo sujeito e devolvido para a sociedade). Essas duas linhas se cruzam e formam a história do comportamento. Sendo assim, o aprendizado tem papel crucial no processo de desenvolvimento cognitivo, pois a aprendizagem é dialética. 
Dessa forma, vale ressaltar a importância da heterogenia, característica presente em qualquer grupo que possibilita a troca de experiências, contextos familiares e visões diferenciadas de mundo, aumentando as possibilidades de mediação. Esse olhar não se volta ao que o indivíduo já consegue realizar, mas ao que pode ser construído com a ajuda dos outros. Esse processo é explicado na Teoria da Zona de Desenvolvimento Proximal (ZDP), que se refere ao caminho que o indivíduo percorre para desenvolver funções em processo de amadurecimento e que se tornarão consolidadas e estabelecidas no seu desenvolvimento real. $\mathrm{O}$ indivíduo conseguirá realizar tarefas e problemas relativos à ZDP desde que conte com o apoio e a mediação de pessoas mais experientes.

Propomos que um aspecto essencial do aprendizado é o fato de ele criar uma zona de desenvolvimento proximal; ou seja, o aprendizado desperta vários processos internos de desenvolvimento, que são capazes de operar somente quando a criança interage com pessoas em seu ambiente e quando em cooperação com seus companheiros. Uma vez internalizados, esses processos tornam-se parte das aquisições do desenvolvimento independente da criança. (VYGOTSKY, 1989, p. 101).

A aprendizagem só se torna cognoscível para o ser humano se houver o entendimento da ação benéfica que irá gerar a interação dos indivíduos. As possibilidades que ela proporciona para o desenvolvimento humano permitem pensar que essa é uma das formas de se trabalhar o tema da violência doméstica e familiar contra a mulher nos espaços escolares. Daí sua relevância no contexto educacional para que educadores o abordem de maneira crítica e construtiva num ensino de qualidade, com práticas que promovam a autonomia de seus estudantes por meio do debate e da reflexão sobre as possibilidades de mudança.

\section{CONSIDERAÇÕES FINAIS}

Após a revisão de literatura realizada, verifica-se que a violência doméstica e familiar contra a mulher é uma questão cultural arraigada na sociedade brasileira, razão pela qual é fundamental que pofissionais estejam preparados para problematizar, dialogar e orientar estudantes do ensino fundamental da rede estadual das cidades de Jataí e Rio Verde, haja vista que eles precisam estar inseridos nas questões sociais de seu tempo, não de forma isolada ou distante, mas próximo de sua realidade e de seus questionamentos e necessidades atuais, bem como dos fatores sociais e culturais, dos direitos e deveres enquanto cidadãos. A mudança de comportamento das novas gerações precisa estar assegurada para fomentar práticas sociais não agressivas. 
A educação holística e democrática para prevenção da violência é um modelo de escolarização que cria condições para o caráter formativo, socializador e não agressivo. É a natureza formativa/socializadora da escola que contribui na desconstrução de comportamentos violentos contra a mulher, intensificados nos dois últimos anos com a prevalência da pandemia da covid-19. A situação se agrava quando se sabe que muitas crianças presenciam esses momentos de agressão vivenciados em suas famílias. Por isso, os conteúdos escolares devem estar em consonância com as questões sociais de cada momento histórico, como recomendam os Paramentos Curriculares Nacionais (PCN). 


\section{Referências}

ADEODATO, Vanessa Gurgel et al. Qualidade de vida e depressão em mulheres vítimas de seus parceiros. Revista de Saúde Pública, v. 39, n. 1, fev. 2005. Disponível em: www.scielo.br/pdf/rsp/v39n1/14.pdf. Acesso em: 28 set. 2020.

ANTUNES, Mitsuko Aparecida; MEIRA, Maria Eugênia (org.). Psicologia escolar: Práticas Críticas. São Paulo: Casa de Psicólogo, 2003.

BRASIL. Lei $n^{\circ} 11.340$, de 7 de agosto de 2006. Cria mecanismos para coibir a violência doméstica e familiar contra a mulher. Disponível em:

http://www.planalto.gov.br/ccivil_03/_ato2004-2006/2006/lei/111340.htm. Acesso em 26 set. 2020.

BRASIL. Ministério da Educação. Parecer CNE/CEB n 11/2010, aprovado em 7 de julho de 2010. Disponível em: http://portal.mec.gov.br/conaes-comissao-nacional-de-avaliacaoda-educacao-superior/323-secretarias-112877938/orgaos-vinculados-82187207/15074-ceb2010-sp-1493348564. Acesso em: 10 jun. 2021.

DAHLBERG, Linda L.; KRUG, Etienne G. Violência: um problema global de saúde pública. Ciência \& Saúde Coletiva, 11(Sup), p.1163-1178, 2007. Disponível em: https://www.scielo.br/pdf/csc/v11s0/a07v11s0.pdf. Acesso em: 25 set. 2020.

FERNANDES, Florestan. A revolução burguesa no Brasil: ensaio de interpretação sociológica. 5. ed. São Paulo: Globo, 2005. 504 p.

LAKATOS, Eva Maria; MARCONI, Marina de Andrade. Metodologia do trabalho cientifico: procedimentos básicos, pesquisa bibliográfica, projeto e relatório, publicações e trabalhos científicos. São Paulo: Ed. Atlas, 2013.

MANACORDA, Mario Alighiero. História da educação: da antiguidade aos nossos dias. São Paulo. Ed. Cortez. 1999.

MANACORDA, Mario Alighiero. Marx e a pedagogia moderna. Trad. Newton Ramom de Oliveira. São Paulo: Cortez, Autores Associados, 1991.

MÉSZÁROS, István. Para além do capital. São Paulo: Boitempo, 2002.

PATTO, Maria Helena Souza. Psicologia e Ideologia: uma introdução à psicologia escolar. São Paulo: Ed. T. A. Queiroz, 1988.

VYGOTSKY, Lev Semenovitch. A formação social da mente. 3. ed. São Paulo: Livraria Martins Fontes Editora Ltda, 1989.

Recebido em: 06/08/2021

Aceito em: 30/08/2021

Publicado online em: 02/09/2021 